\title{
Comparison of bivariate and multivariate joint analyses on the selection loss of beef cattle
}

\author{
V.B. Pedrosa ${ }^{1}$, E. Groeneveld ${ }^{2}$, J.P. Eler ${ }^{3}$ and J.B.S. Ferraz ${ }^{3}$ \\ ${ }^{1}$ Laboratório de Estudos em Melhoramento Animal, Departamento de Zootecnia, \\ Universidade Estadual de Ponta Grossa, Ponta Grossa, PR, Brasil \\ ${ }^{2}$ Department of Animal Breeding and Genetic Resources, \\ Friedrich Loeffler Institute, Institute of Farm Animal Genetics, \\ Neustadt, Germany \\ ${ }^{3}$ Grupo de Melhoramento Animal e Biotecnologia, \\ Departamento de Ciências Básicas, Universidade de São Paulo, \\ Pirassununga, SP, Brasil
}

Corresponding author: V.B. Pedrosa

E-mail: vbpedrosa@uepg.br

Genet. Mol. Res. 13 (2): 4036-4045 (2014)

Received September 26, 2014

Accepted December 13, 2013

Published May 23, 2014

DOI http://dx.doi.org/10.4238/2014.May.23.14

\begin{abstract}
For genetic evaluation of beef cattle, univariate or bivariate analyses are often performed as an alternative to decrease the complexity of matrices and mathematical models compared to multivariate analysis, which considers a larger number of joint traits. The use of bivariate methods to calculate genetic predictors may cause bias in the estimation of breeding values and, as a consequence, reclassification of the rank of top-selected sires, resulting in a loss of genetic gain in future generations. The objective of this study was to compare the bivariate and multivariate joint methods of genetic evaluation, verifying the selection loss, and reclassification of the ranking of the best animals with different selection intensities. Records of 431,224 Nellore breed animals were evaluated for birth weight, weaning weight, post-weaning gain, muscle score, scrotal circumference, and selection index. The pedigree file consisted of 505,848 animals, including 218,727 males and
\end{abstract}


287,121 females. The predicted breeding values were obtained using the program PEST 2, and the complete pedigree analysis was performed by the PopReport software. The results showed that, for the four different selection intensities considered (TOP 10 and 1, 10, and 30\%), selection loss and reclassification of animals in ranking, were detected for all traits evaluated when the two methods of analysis were compared.

Key words: Genetic evaluation; Breeding value; Selection index; Sire ranking; Beef cattle

\section{INTRODUCTION}

Multivariate joint analyses have been recommended for genetic evaluations of animals (Henderson and Quaas, 1976; Thompson and Meyer, 1986; Kovac and Groeneveld, 1990; Meyer, 1991), since they can improve the accuracy of the evaluation, and consequently, the selection response, making it possible to eliminate or reduce the bias because of the selection applied of certain variables (Pollak et al., 1984; Schaeffer, 1984). However, because the computational demand is increased by the number of (co)variances that have to be estimated together in the multivariate models, univariate or bivariate analyses are often performed (Henderson, 1984; Meyer et al., 1993; Villanueva et al., 1993; Ramírez-Valverde et al., 2007).

In recent years, improvements in computing resources allow easier handling of large data sets and models considering traits that can be analyzed jointly with all traits included in the selection process (Noguera et al., 2002). Several studies (Eler et al., 1995; Bennett and Gregory, 1996; Ramírez-Valverde et al., 2007) have demonstrated that multivariate joint analyses are feasible and present better results than bivariate analyses for different breeds of beef cattle.

The Nellore breed accounts for $80 \%$ of the registered zebu (Bos indicus) cattle in Brazil. The main feature of the breed is its adaptability to tropical conditions, although the herds exhibit large differences in growth and fertility potential among regions. This variability represents potential for genetic improvement in the production and reproduction ambits. The traits associated with growth, such as birth weight (BW), weaning weight (WW), postweaning gain (PWGAIN), and muscle score (MUSC), and those related to reproduction, such as scrotal circumference (SC), are important for the efficiency of production systems and are constantly considered as selection criteria. For that reason, comparisons should be performed in one multivariate joint analysis to avoid the bias on the predicted genetic values (Pollak and Quaas, 1981; Henderson, 1984). The objective of this study was to compare one multivariate joint analysis to a number of bivariate analyses by computing the loss of selection response for growth and reproduction traits (BW, WW, PWGAIN, MUSC, and SC) as well for the selection index (INDEX) in the genetic evaluation of Nellore cattle raised in Brazil.

\section{MATERIAL AND METHODS}

\section{Data information}

The data used in this research came from the Agro-Pecuária CFM, Ltda., which is a cattle breeding company located in the tropical southeastern and central-western region of 
Brazil. This company sells around 2000 young Nellore replacement bulls out of approximately 7000 weaned calves per year. Both bulls and heifers were maintained on high-quality pasture (40\% Brachiaria brizantha, 50\% Panicum maximum, and 10\% others) and received mineral supplementation through the years.

Records of 431,224 animals born from 1984 to 2008 were included in the breeding value estimation. The pedigree data were composed of 505,848 animals, including 218,727 males and 287,121 females. The average age of males and females at reproduction was 6.1 and 7.0 years, respectively, and the generation interval of the studied population was 6.3. The pedigree completeness average, which represents the proportion of known ancestors in each generation (MacCluer et al., 1983) for the animals born within the last 10 years were 43.2, 40.1, 35.1, $29.1,24$, and $20.1 \%$ for $1,2,3,4,5$, and 6 generations, respectively. The animals were distributed over 3265, 8144, 858, 730, and 389 contemporary groups (CG) for BW, WW, PWGAIN, MUSC, and SC, respectively. The description of the data set structure is given in Table 1.

\begin{tabular}{|c|c|c|c|c|c|}
\hline Variable & Records & Mean & $\mathrm{Std}^{\mathrm{a}}$ & Minimum & Maximum \\
\hline BW (kg) & 196.194 & 30.98 & 3.61 & 10.00 & 65.00 \\
\hline WW (kg) & 428.890 & 171.30 & 28.25 & 60.00 & 337.00 \\
\hline PWGAIN (kg) & 128.603 & 112.46 & 33.03 & 0.50 & 334.34 \\
\hline MUSC (score) & 118.801 & 3.57 & 0.94 & 1.00 & 6.00 \\
\hline $\mathrm{SC}(\mathrm{cm})$ & 58.381 & 27.14 & 3.38 & 10.00 & 44.00 \\
\hline
\end{tabular}

$\mathrm{BW}=$ birth weight; $\mathrm{WW}=$ weaning weight; $\mathrm{PWGAIN}=$ post-weaning gain; $\mathrm{MUSC}=$ muscle score; $\mathrm{SC}=$ scrotal circumference. ${ }^{\text {aStandard deviation. }}$

The data set analyses were carried out in the Department of Animal Breeding and Genetic Resources of the Friedrich Loeffler Institut (FLI), Germany, in partnership with the Animal Breeding and Biotechnology Group of the College of Animal Science and Food Engineering, University of São Paulo, Brazil (GMAB, FZEA, USP). Besides the traits that were considered in this study (BW, WW, PWGAIN, MUSC, and SC), the INDEX was also calculated. For the INDEX composition, each component was obtained using the ratio between the expected progeny differences (EPD) and its genetic standard deviation, where a specific weight was attributed to each included trait (WW, PWGAIN, MUSC, and SC) as described below.

$$
\mathrm{INDEX}=\frac{2 . \mathrm{EPD}_{\mathrm{WW}}}{\sigma_{\mathrm{g}} \mathrm{wW}}+\frac{4 . \mathrm{EPD}_{\mathrm{PWGAN}}}{\sigma_{g_{\mathrm{PWGAN}}}}+\frac{2 . \mathrm{EPD}_{\mathrm{MUSC}}}{\sigma_{\mathrm{g}_{\mathrm{MUSC}}}}+\frac{2 . \mathrm{EPD}_{\mathrm{SC}}}{\sigma_{g_{\mathrm{SC}}}} \quad \text { (Equation 1) }
$$

\section{Statistical models of analysis}

For BW, the model considered dam age, Julian date of birth (both linear and quadratic covariates), and contemporary group as fixed effects; the maternal permanent environmental, direct genetic, and maternal genetic effects were considered as random effects. For WW, the same model was used, but the fixed effect age at weaning season was added as a linear covariate.

The model used for PWGAIN was formed with dam age, Julian date of birth (both linear and quadratic covariates), age at weaning, age at post-weaning measurement (both linear covariates), and contemporary group as fixed effects. The management group at weaning, direct 
genetic effects, and maternal genetic effects were considered as random effects. A similar model was utilized for SC and MUSC, excluding ages at the measurement season, and including the age at scrotal circumference measurement season (linear covariate) and age at muscle score measurement (linear covariate), respectively. Additionally, the maternal genetic effect for MUSC was excluded because it did not have a significant effect, as shown in previous studies. In matrix notation, all models that were utilized in this study may be presented together as follows:

$$
y=\mathrm{X} \beta+\mathrm{Zg}+\mathrm{Mm}+\mathrm{Ww}+\mathrm{Pp}+e
$$

(Equation 2)

where, $y$ is an $\mathrm{N} x 1$ vector of records, $\beta$ denotes the vector of fixed effects, $X$ is the matrix that associates $\beta$ with $y, g$ is the vector of direct genetic effects, $Z$ is the matrix that associates $g$ with $y, m$ is the vector of maternal genetic effects, $M$ is the matrix that associates $m$ with $y, w$ is the vector of management group at weaning effects, $W$ is the matrix that associates $w$ with $y, p$ is the vector of permanent environmental plus non-additive genetic effects contributed by dams to records of their progeny, $P$ is the matrix that associates $p$ with $y$, and $e$ is the vector of residual effects that are peculiar to observations and are not explained by other parts of the model. For the multivariate joint analysis, the model expectation is:

$$
\mathrm{E}\left[\begin{array}{c}
\mathrm{Y}_{1} \\
\mathrm{Y}_{2} \\
\mathrm{Y}_{3} \\
\mathrm{Y}_{4} \\
\mathrm{Y}_{5}
\end{array}\right]=\left[\begin{array}{ccccc}
\mathrm{X}_{1} & 0 & 0 & 0 & 0 \\
0 & \mathrm{X}_{2} & 0 & 0 & 0 \\
0 & 0 & \mathrm{X}_{3} & 0 & 0 \\
0 & 0 & 0 & \mathrm{X}_{4} & 0 \\
0 & 0 & 0 & 0 & \mathrm{X}_{5}
\end{array}\right]\left[\begin{array}{l}
\beta_{1} \\
\beta_{2} \\
\beta_{3} \\
\beta_{4} \\
\beta_{5}
\end{array}\right]
$$

where, the subscripts $1,2,3,4$, and 5 represent BW, WW, PWGAIN, MUSC, and SC, respectively. The (co)variance matrix for genetic effects is $G=G_{0} \otimes \mathrm{A}$, where A is the genetic relationship matrix and $\mathrm{G}_{0}$ is the matrix (of order 9) as follows.

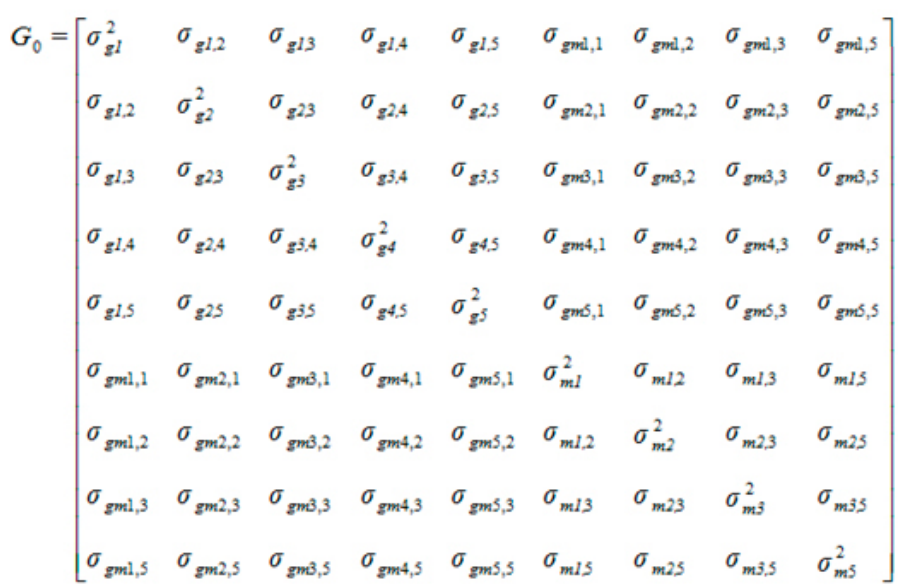

The (co)variance matrix for management group at weaning effects is $\mathrm{W}=\mathrm{W}_{0} \otimes \mathrm{I}_{\mathrm{w}}$, where $\mathrm{I}_{\mathrm{W}}$ is the identity matrices of appropriate order for $w$ management groups, and $\mathrm{W}_{0}$ is the matrix (of order 3 ) as follows. 


$$
W_{0}=\left[\begin{array}{ccc}
\sigma_{w 3}^{2} & \sigma_{w 3,4}^{2} & \sigma_{w 3,5}^{2} \\
\sigma_{w 3,4}^{2} & \sigma_{w 4}^{2} & \sigma_{w 4,5}^{2} \\
\sigma_{w 3,5}^{2} & \sigma_{w 4,5}^{2} & \sigma_{w 5}^{2}
\end{array}\right]
$$

The (co)variance matrix for permanent environmental effects is $\mathrm{P}=\mathrm{P}_{0} \otimes \mathrm{I}_{\mathrm{C}}$, where $\mathrm{I}_{\mathrm{C}}$ is the identity matrices of appropriate order for c cows, and $\mathrm{P}_{0}$ is the matrix (of order 2 ) that is applied for BW and WW. $R$ is the residual (co)variance matrix (of order 5) between the five traits.

For the bivariate model, WW was considered as a permanent trait in each bivariate analysis because it contains the most information regarding the selection decisions, as mentioned by Meyer et al. (1993). However, if the selection criteria consist of five traits jointly, the assumed (co)variance matrix for genetic effects is $G=G_{1} \otimes \mathrm{A}$, where A is the genetic relationship matrix and $\mathrm{G}_{1}$ is the matrix (of order 9) setting the covariances not related to WW to zero as follows.

$$
G_{0}=\left[\begin{array}{lllllllll}
\sigma_{g 1}^{2} & \sigma_{g 1,2} & 0 & 0 & 0 & 0 & 0 & 0 & 0 \\
\sigma_{g 1,2} & \sigma_{g 2}^{2} & \sigma_{g 23} & \sigma_{g 2,4} & \sigma_{g 25} & \sigma_{g m 2,1} & \sigma_{g m 2,2} & \sigma_{g m 2,3} & \sigma_{g m 2,5} \\
0 & \sigma_{g 23} & \sigma_{g s}^{2} & 0 & 0 & 0 & 0 & 0 & 0 \\
0 & \sigma_{g 2,4} & 0 & \sigma_{g 4}^{2} & 0 & 0 & 0 & 0 & 0 \\
0 & \sigma_{g 25} & 0 & 0 & \sigma_{g 5}^{2} & 0 & 0 & 0 & 0 \\
0 & \sigma_{g m 2,1} & 0 & 0 & 0 & \sigma_{m l}^{2} & \sigma_{m 1,2} & 0 & 0 \\
0 & \sigma_{g m 2,2} & 0 & 0 & 0 & \sigma_{m l, 2} & \sigma_{m 2}^{2} & \sigma_{m 23} & \sigma_{m 25} \\
0 & \sigma_{g m 2,3} & 0 & 0 & 0 & 0 & \sigma_{m 23} & \sigma_{m s}^{2} & 0 \\
0 & \sigma_{g m 2,5} & 0 & 0 & 0 & 0 & \sigma_{m 25} & 0 & \sigma_{m 5}^{2}
\end{array}\right]
$$

(Equation 6)

In this present study, similar to the above, the (co)variance matrix for the management group at weaning effects is $\mathrm{W}=\mathrm{W}_{1} \otimes \mathrm{I}_{\mathrm{W}}$, where $\mathrm{I}_{\mathrm{W}}$ is the identity matrices of appropriate order for w management groups, and $\mathrm{W}_{1}$ is the matrix (of order 3 ) set to zero for all covariance. In the bivariate model with WW as a fixed trait, the mentioned group effects are not correlated as follows.

$$
W_{1}=\left[\begin{array}{ccc}
\sigma_{w 9}^{2} & 0 & 0 \\
0 & \sigma_{w 4}^{2} & 0 \\
0 & 0 & \sigma_{w 5}^{2}
\end{array}\right]
$$

(Equation 7) 
The (co)variance matrix for permanent environmental $\left(\mathrm{P}_{1}\right)$ and residual $\left(\mathrm{R}_{1}\right)$ effects for the bivariate model are equal to those considered in the multivariate joint analysis, although the covariance would be set to zero for those that are not correlated to WW.

\section{Selection loss}

It can be safely assumed that selection for just two traits is impossible without affecting other important production traits. Thus, the breeding values from the multivariate joint analysis were taken as the true breeding values. Therefore, selection of the top animals from these best linear unbiased predictions (BLUPs) will produce the maximum genetic response. Any other group of breeding animals will result in a reduction of the genetic value average for any selection intensity.

In the first step, all animals included in the data set were evaluated. Four selection intensities applied to the total data set were considered (TOP 10 and 1, 10, and 30\%) to calculate the percentage of loss, which was computed as recommended by Peškovičová et al. (2004). The two means $\left(\mathrm{X}_{M U L T I}\right.$ and $\left.\mathrm{X}_{B I}\right)$ of the EPD, which were the basis for the selection loss computation, were obtained. First, for each trait, the EPD average of the selected animals was calculated by the multivariate joint method (MULTI); subsequently, the EDP results from multivariate joint analyses for the corresponding selected animals were obtained by the bivariate model (BI) because these results were considered the true breeding values.

$$
\text { Percentage of selection loss }=100-\left[\left(\mathrm{X}_{B I} / \mathrm{X}_{M U L T}\right) \times 100\right] \quad \text { (Equation 8) }
$$

As a second step, all males born between 1998 and 2005 were analyzed; at this age, they could be selected as sires, who will contribute genetically to the next generations. For this case, as a verification of the genetic loss, the ranking of the selected TOP 10 best males were evaluated for all traits. Additionally, INDEX was determined from the MULTI and BI analyses. After that, the average values for INDEX from the MULTI and BI methods were graphically verified for the four selection intensities considered.

For all analyses, predictions of breeding values were obtained using the PEST program (Groeneveld et al., 2009). Restricted maximum likelihood (REML) estimates calculated using the VCE 6.0 package (Groeneveld et al., 2008) were used as input parameters for the covariance matrices. The pedigree report analysis was performed by the PopReport software (Groeneveld et al., 2009).

\section{RESULTS}

The average of the EPD results for each variable studied, including all animals, and the percentages of genetic loss, from the difference between MULTI and BI methods, are represented in Table 2. Because MULTI was safely assumed as the true genetic value, all obtained EPD averages were higher for MULTI than BI, especially with low selection intensities.

For the four different selection intensities, TOP 10 and 1, 10, and $30 \%$, the selection loss partly depended on the selection intensity, and there was a tendency of a decrease 
in the percentage of loss by BW, WW, and INDEX results. Nevertheless, there were exceptions to this tendency, and the selection loss remained substantial for higher levels of selection intensity, as verified for SC, PWGAIN, and MUSC. Among TOP 10 and 30\% intervals, the difference in the EPD average between the methods was constant. BW and WW presented a considerable percentage of loss, especially for the TOP 10 selection intensity (9.09 and 8.43, respectively), as well as MUSC, which showed loss 5.88, 2.44, 4.00, and 6.25 for TOP 10 and 1, 10, and 30\%, respectively. For SC, PWGAIN, and INDEX, the percentages were low and ranged between 1.69 and 2.70 for SC, 1.36 and 2.16 for PWGAIN, and 0.74 and 1.78 for INDEX.

Table 2. Selection loss according to the number of animals selected.

\begin{tabular}{|c|c|c|c|c|c|c|c|c|c|c|c|c|}
\hline \multirow[b]{2}{*}{ Variables } & \multicolumn{3}{|c|}{ TOP 10} & \multicolumn{3}{|c|}{ TOP $1 \%$} & \multicolumn{3}{|c|}{ TOP $10 \%$} & \multicolumn{3}{|c|}{ TOP $30 \%$} \\
\hline & Multia & $\mathrm{Bi}^{\mathrm{b}}$ & $\%{ }^{\mathrm{c}}$ & Multi & $\mathrm{Bi}$ & $\%$ & Multi & $\mathrm{Bi}$ & $\%$ & Multi & $\mathrm{Bi}$ & $\%$ \\
\hline$\overline{\mathrm{BW}}$ & $\begin{array}{r}2.42 \\
(0.22)\end{array}$ & $\begin{array}{r}2.20 \\
(0.35)\end{array}$ & 9.09 & $\begin{array}{c}1.29 \\
(0.20)\end{array}$ & $\begin{array}{c}1.23 \\
(0.24)\end{array}$ & 4.65 & $\begin{array}{c}0.76 \\
(0.24)\end{array}$ & $\begin{array}{c}0.73 \\
(0.26)\end{array}$ & 3.95 & $\begin{array}{c}0.44 \\
(0.28)\end{array}$ & $\begin{array}{c}0.43 \\
(0.29)\end{array}$ & 2.27 \\
\hline WW & $\begin{array}{l}13.29 \\
(0.53)\end{array}$ & $\begin{array}{l}12.17 \\
(0.97)\end{array}$ & 8.43 & $\begin{array}{c}8.54 \\
(0.92)\end{array}$ & $\begin{array}{c}8.15 \\
(1.30)\end{array}$ & 4.57 & $\begin{array}{c}5.67 \\
(1.32)\end{array}$ & $\begin{array}{c}5.47 \\
(1.52)\end{array}$ & 3.53 & $\begin{array}{c}3.71 \\
(1.67)\end{array}$ & $\begin{array}{c}3.62 \\
(1.77)\end{array}$ & 2.43 \\
\hline $\mathrm{SC}$ & $\begin{array}{r}2.17 \\
(0.13)\end{array}$ & $\begin{array}{r}2.13 \\
(0.15)\end{array}$ & 1.84 & $\begin{array}{c}1.18 \\
(0.18)\end{array}$ & $\begin{array}{c}1.16 \\
(0.20)\end{array}$ & 1.69 & $\begin{array}{c}0.66 \\
(0.23)\end{array}$ & $\begin{array}{c}0.65 \\
(0.25)\end{array}$ & 1.52 & $\begin{array}{c}0.37 \\
(0.26)\end{array}$ & $\begin{array}{c}0.36 \\
(0.27)\end{array}$ & 2.70 \\
\hline PWGAIN & $\begin{array}{l}16.13 \\
(1.02)\end{array}$ & $\begin{array}{l}15.91 \\
(1.26)\end{array}$ & 1.36 & $\begin{array}{c}8.35 \\
(1.14)\end{array}$ & $\begin{array}{c}8.20 \\
(1.28)\end{array}$ & 1.80 & $\begin{array}{c}5.09 \\
(1.48)\end{array}$ & $\begin{array}{c}4.98 \\
(1.60)\end{array}$ & 2.16 & $\begin{array}{c}3.19 \\
(1.66)\end{array}$ & $\begin{array}{c}3.13 \\
(1.71)\end{array}$ & 1.88 \\
\hline MUSC & $\begin{array}{r}0.68 \\
(0.02)\end{array}$ & $\begin{array}{r}0.64 \\
(0.04)\end{array}$ & 5.88 & $\begin{array}{c}0.41 \\
(0.05)\end{array}$ & $\begin{array}{c}0.40 \\
(0.06)\end{array}$ & 2.44 & $\begin{array}{c}0.25 \\
(0.07)\end{array}$ & $\begin{array}{c}0.24 \\
(0.08)\end{array}$ & 4.00 & $\begin{array}{c}0.16 \\
(0.07)\end{array}$ & $\begin{array}{c}0.15 \\
(0.08)\end{array}$ & 6.25 \\
\hline INDEX & $\begin{array}{c}10.65 \\
(0.38)\end{array}$ & $\begin{array}{l}10.46 \\
(0.58)\end{array}$ & 1.78 & $\begin{array}{c}6.50 \\
(0.74)\end{array}$ & $\begin{array}{c}6.40 \\
(0.85)\end{array}$ & 1.54 & $\begin{array}{c}4.18 \\
(1.06)\end{array}$ & $\begin{array}{c}4.12 \\
(1.12)\end{array}$ & 1.44 & $\begin{array}{c}2.69 \\
(1.27)\end{array}$ & $\begin{array}{c}2.67 \\
(1.30)\end{array}$ & 0.74 \\
\hline
\end{tabular}

$\overline{\mathrm{INDEX}}=$ empirical selection index. ${ }^{\mathrm{a}} \mathrm{Multi}=$ Expected progeny differences from multivariate joint analysis. ${ }^{\mathrm{b}} \mathrm{Bi}$ $=$ Expected progeny differences from multivariate joint analysis, for the animals selected from bivariate analysis. ${ }^{c} \%=$ Percentage of genetic loss. Standard deviation results are in parentheses. For other abbreviations, see legend to Table 1.

As a second part of this research, the influence of selection loss in males was studied because the selection of the very best sires is affected by the bias that is generated by the use of an incorrect selection method. The re-ranking percentages of sires selected in the TOP 10 selection intensity are represented in Table 3 by MULTI and BI methods for BW, WW, PWGAIN, MUSC, SC, and INDEX.

For the five studied traits and INDEX, the best animal was the same for both methods considered, but for WW, MUSC, and INDEX, a re-ranking was established from the second animal, indicating selection loss from the beginning of the classification. For the other traits, a similar tendency was observed: for BW, SC, and PWGAIN, the altered ranking occurred from the fourth, fifth, and sixth position, respectively. For higher selection intensities (not shown), it is obviously expected that a superior variation in the ranking occurs, given that more animals will be involved in the comparison; because a position in the ranking is modified, the tendency of the others is to randomize.

Figure 1 represents the comparison of the INDEX unit decrease for both methods for the four selection intensities, where those of BI were smaller than those of MULTI for all selected populations. For TOP 10 and 1, 10, and 30\%, the INDEX units decreased approximately from $90,50,30$, and $20 \%$ of the selected animals, respectively. These reductions in the INDEX units in the BI methodology demonstrate the genetic loss for selection intensities that were associated with not considering the most correct system of analysis. 
Table 3. Re-ranking percentage of males selected (TOP 10) by multivariate joint and bivariate methods for birth weight (BW), weaning weight (WW), post-weaning gain (PWGAIN), muscle score (MUSC), scrotal circumference (SC), and empirical selection index (INDEX).

\begin{tabular}{|c|c|c|c|c|c|c|c|c|c|}
\hline \multicolumn{5}{|c|}{$\mathrm{BW}$} & \multicolumn{5}{|c|}{ WW } \\
\hline Animal & Multi $^{\mathrm{a}}$ & Animal & $\mathrm{Bi}^{\mathrm{b}}$ & $\%^{\mathrm{c}}$ & Animal & Multi $^{\mathrm{a}}$ & Animal & $\mathrm{Bi}^{\mathrm{b}}$ & $\%^{\mathrm{c}}$ \\
\hline$\overline{\text { ES211599 }}$ & 2.96 & ES211599 & 2.96 & 70 & SF292998 & 13.72 & SF292998 & 13.72 & 90 \\
\hline SF152700 & 2.29 & SF 152700 & 2.29 & & ART20904 & 13.54 & PO124099 & 13.16 & \\
\hline CH928200 & 2.29 & CH928200 & 2.29 & & PO124099 & 13.16 & CH865299 & 13.09 & \\
\hline XX452198 & 2.23 & PC353798 & 2.15 & & CH865299 & 13.09 & PO125099 & 12.78 & \\
\hline PC353798 & 2.15 & CH577001 & 2.10 & & PO125099 & 12.78 & PO130799 & 12.75 & \\
\hline CH577001 & 2.10 & CH865199 & 2.04 & & PO130799 & 12.75 & SF192904 & 12.24 & \\
\hline CH865199 & 2.04 & PO101798 & 1.95 & & SF192904 & 12.24 & $\mathrm{CH} 444401$ & 12.22 & \\
\hline CH200701 & 2.03 & SF422001 & 1.91 & & CH444401 & 12.22 & AR237601 & 12.07 & \\
\hline CH922000 & 2.02 & PC515200 & 1.91 & & SF367600 & 12.21 & PO101798 & 11.46 & \\
\hline \multirow[t]{2}{*}{ PO096698 } & 2.02 & LG220304 & 1.80 & & PO123799 & 12.19 & PC353798 & 11.02 & \\
\hline & \multicolumn{3}{|c|}{$\mathrm{SC}$} & & \multicolumn{5}{|c|}{ PWGAIN } \\
\hline$\overline{\text { SF464701 }}$ & 2.22 & SF464701 & 2.22 & 60 & SF432699 & 15.69 & SF432699 & 15.69 & 50 \\
\hline LA368900 & 2.17 & LA368900 & 2.17 & & CH219302 & 15.21 & $\mathrm{CH} 219302$ & 15.21 & \\
\hline SF160003 & 2.16 & SF160003 & 2.16 & & $\mathrm{CH} 090500$ & 13.34 & $\mathrm{CH} 090500$ & 13.34 & \\
\hline SF006199 & 2.07 & SF006199 & 2.07 & & CH301301 & 13.28 & CH301301 & 13.28 & \\
\hline SF447603 & 2.06 & SF027898 & 2.04 & & SF160299 & 12.98 & SF160299 & 12.98 & \\
\hline SF027898 & 2.04 & CH039102 & 2.01 & & CH327004 & 12.68 & SF417302 & 12.47 & \\
\hline CH039102 & 2.01 & SF425402 & 2.01 & & SF 274300 & 12.65 & SF513104 & 12.46 & \\
\hline SF425402 & 2.01 & SF299003 & 2.00 & & SF417302 & 12.47 & CH748299 & 12.03 & \\
\hline SF299003 & 2.00 & SF032701 & 2.00 & & SF513104 & 12.46 & CH311501 & 11.98 & \\
\hline \multirow[t]{2}{*}{ SF032701 } & 2.00 & SF020898 & 1.94 & & ART07704 & 12.41 & FN162502 & 11.76 & \\
\hline & \multicolumn{3}{|c|}{ MUSC } & & \multicolumn{5}{|c|}{ INDEX } \\
\hline SF370303 & 0.65 & SF370303 & 0.65 & 90 & SF162003 & 9.89 & SF162003 & 9.89 & 90 \\
\hline CH312904 & 0.61 & ART07704 & 0.60 & & CH219302 & 9.80 & SF031699 & 9.68 & \\
\hline ART07704 & 0.60 & SF109602 & 0.60 & & SF031699 & 9.68 & SF084602 & 9.55 & \\
\hline SF109602 & 0.60 & SF157103 & 0.60 & & SF084602 & 9.55 & SF417302 & 9.42 & \\
\hline SF157103 & 0.60 & CH332804 & 0.60 & & SF417302 & 9.42 & SF376203 & 9.05 & \\
\hline CH332804 & 0.60 & SF361700 & 0.60 & & CH327004 & 9.29 & SF083798 & 8.84 & \\
\hline SF361700 & 0.60 & SF356603 & 0.58 & & SF513104 & 9.16 & LG310003 & 8.79 & \\
\hline ART20904 & 0.58 & SF084602 & 0.56 & & SF376203 & 9.05 & SF444902 & 8.72 & \\
\hline SF356603 & 0.58 & ART02504 & 0.53 & & CH312904 & 9.00 & $\mathrm{CH} 312701$ & 8.69 & \\
\hline ART01003 & 0.56 & ART07803 & 0.53 & & CH308604 & 8.97 & ART20904 & 8.63 & \\
\hline
\end{tabular}

${ }^{a}$ Multi $=$ Expected progeny differences from multivariate joint analysis. ${ }^{b} \mathrm{Bi}=$ Expected progeny differences from multivariate joint analysis for the selected males from bivariate analysis. ${ }^{c} \%=$ Percentage of re-classification of the selected animals for both methods.

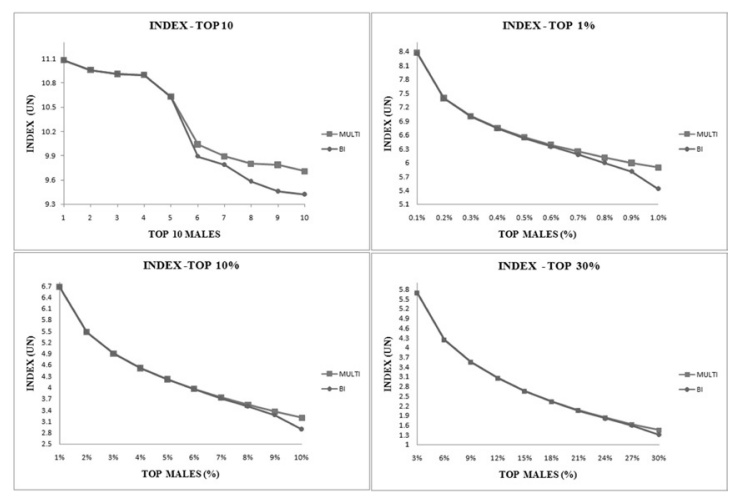

Figure 1. Index selection for TOP 10 and 1, 10, and 30\% males by using multivariate joint and bivariate methods. MULTI = index unit from multivariate joint analysis; BI = index unit from multivariate joint analysis for the selected males from bivariate analysis; and selected males $(\%)=$ percentage of the total selected males for each selection class (TOP 10 and 1, 10, and 30\%). 


\section{DISCUSSION}

Most animal breeding programs use the BI method in the evaluations, but previous experimental analyses motivated the realization of this study (Henderson, 1984; Meyer et al., 1993; Villanueva et al., 1993; Ramírez-Valverde et al., 2007) because it was noted that BI and MULTI analyses led to different patterns of responses in the estimated breeding values. These differences may be explained by the bias generated because of considering the (co)variances between traits as zero (Henderson and Quaas, 1976; Schaeffer, 1984; Thompson and Meyer, 1986; Kovac and Groeneveld, 1990). The more that the (co)variances among important traits are not considered, the more the estimated breeding values deviate from the true value.

Although the results of selection loss percentage were low considering the entire population studied, the presence of bias in the BI method was evident. This low difference in the EPD average for the methods can be explained by the fact that, regardless of the methodology, the attribution of high breeding values for the best animals of the population is conditioned upon the elevated number of relatives of the top animals, as demonstrated by Falconer and Mackay (1996). For this reason, it is expected that most of the best animals, which have a large amount of related pedigree information, would be present in the MULTI and BI top rankings, concomitantly.

Our research also demonstrated that the greatest influence of not using the most appropriate method of animal breeding evaluation was the re-ranking that was caused by the analysis bias. Pollak et al. (1984) had warned the potential problems of misranking when genetic evaluation was conducted while disregarding the genetic correlation between important traits. The authors concluded that by not utilizing the multivariate method, there was a tendency to over-predict the worst bulls and under-predict the best bulls. For this reason, many sires still have been used as top bulls from seedstock herds, when in fact other better animals are discarded because they are considered to be inferior.

Considering the unbiased estimates of breeding values as the true value for the trait's aim of selection directly influences the empirical index calculation because it depends on the reliability of the traits used in the computation. Most countries provide breeding values from univariate or bivariate analyses; therefore, they also calculate and publish total merit indices from these breeding values. In situations where correlations between traits are not taken into account, these breeding values will often be biased (Henderson, 1975; Schaeffer et al., 1998; Lassen et al., 2007).

The loss in the empirical index values for the four different intensities of selection that were considered demonstrated a differentiation in the selection according to the methodology, regardless of the number of animals selected. According to Groeneveld et al. (1992), the computational outlay that is required by MULTI analyses is considered irrelevant to the possible genetic gain in each animal generation for the selection closer to the reality of the sires that are used in the herd.

\section{CONCLUSION}

The importance of using robust types of analysis that approximate the calculation of the estimated value relative to the real value should not be ignored. Because computational advances allow quick calculations, multivariate solutions can provide highly accurate results and an index that is highly reliable and could help the breeder in selection. 


\section{ACKNOWLEDGMENTS}

Research supported by Fundação de Amparo à Pesquisa do Estado de São Paulo FAPESP. We are grateful to Agropecuária CFM Ltda. (Agricultural Livestock CFM, Ltd.) for supplying the data set.

\section{REFERENCES}

Bennett GL and Gregory KE (1996). Genetic (co)variances among birth weight, 200-day weight, and postweaning gain in composites and parental breeds of beef cattle. J. Anim. Sci. 74: 2598-2611.

Eler JP, Van Vleck LD, Ferraz JB and Lôbo RB (1995). Estimation of variances due to direct and maternal effects for growth traits of Nelore cattle. J. Anim. Sci. 73: 3253-3258.

Falconer DS and Mackay TFC (1996). Introduction to Quantitative Genetics. 4th edn. (Harlow, ed.). Longman.

Groeneveld E, Kovac M, Wang TL and Fernando RL (1992). Computing algorithms in a general-purpose BLUP package for multivariate prediction and estimation. Arch. Tierzucht 35: 399-412.

Groeneveld E, Kovac M and Mielenz N (2008). VCE User's Guide and Reference Manual. Version 6.0. Department of Animal Science. University of Illinois, Urbana.

Groeneveld E, Kovac M and Mielenz N (2009). PEST User's Guide and Reference Manual. Version 2.0. Department of Animal Science. University of Illinois, Urbana.

Henderson CR (1975). Best linear unbiased estimation and prediction under a selection model. Biometrics 31: 423-447.

Henderson CR (1984). Estimation of variances and covariances under multiple trait models. J. Dairy Sci. 67: 1581-1589.

Henderson CR and Quaas RL (1976). Multiple trait evaluation using relatives' records. J. Anim. Sci. 43: 1188-1197.

Kovac M and Groeneveld E (1990). Multivariate genetic evaluation in swine combining data from different testing schemes. J. Anim. Sci. 68: 3507-3522.

Lassen J, Sorensen MK, Madsen P and Ducrocq V (2007). An approximate multitrait model for genetic evaluation in dairy cattle with a robust estimation of genetic trends. Genet. Sel. Evol. 39: 353-367.

MacCluer JW, Boyce AJ, Dyke B, Weitkamp LR, et al (1983). Inbreeding and pedigree structure in Standardbred horses. J. Hered. 74: 394-399.

Meyer K (1991). Estimating variances and covariances for multivariate animal models by restricted maximum likelihood. Genet. Sel. Evol. 23: 67-83.

Meyer K, Carrick MJ and Donnelly BJ (1993). Genetic parameters for growth traits of Australian beef cattle from a multibreed selection experiment. J. Anim. Sci. 71: 2614-2622.

Noguera JL, Varona L, Babot D and Estany J (2002). Multivariate analysis of litter size for multiple parities with production traits in pigs: I. Bayesian variance component estimation. J. Anim. Sci. 80: 2540-2547.

Peškovičová D, Groeneveld E and Wolf J (2004). Effect of genetic groups on the efficiency of selection in pigs. Livest. Prod. Sci. 88: 213-222.

Pollak EJ and Quaas RL (1981). Monte Carlo study of genetic evaluations using sequentially selected records. J. Anim. Sci. 52: 257-264.

Pollak EJ, van der Werf J and Quaas RL (1984). Selection bias and multiple trait evaluation. J. Dairy Sci. 67: 1590-1595.

Ramírez-Valverde R, Hernández Alvarez OC, Núñez-Domínguez R, Ruíz-Flores A, et al. (2007). Análisis univariado vs multivariado en la evaluación genética de variables de crecimiento en dos razas bovinas. Agrociencia 41: 271-282.

Schaeffer LR (1984). Sire and cow evaluation under multiple trait models. J. Dairy Sci. 67: 1567-1580.

Schaeffer LR, Schenkel FS and Fries LA (1998). Selection bias on animal model evalation. Proc. 6th World Congr. Genet. Appl. Livest. Prod. 25: 501-508.

Thompson R and Meyer K (1986). A review of theoretical aspects in the estimation of breeding values for multi-trait selection. Livest. Prod. Sci. 15: 299-313.

Villanueva B, Wray NR and Thompson R (1993). Prediction of asymptotic rates of response from selection on multiple traits using univariate and multivariate best linear unbiased predictors. Anim. Sci. 57: 1-13. 